\title{
Educational Website based on Integration between Web- based Simulation and Retrieval Strategies
}

\author{
A.F.ElGamal \\ Department of CS \\ Mansoura University \\ Egypt
}

\begin{abstract}
World Wide Web (WWW) simulation is an engineering tool with enormous potential impact on education, by combining the modeling capabilities of traditional simulation tools with the communication capability of the Internet. This paper describes educational website based on integration between web-based simulation and retrieval strategies. Learners were classified according to their retrieval strategies (organizational - rehearsal) and were exposed to the proposed educational website which explained computer networking concepts in two different formats. The first used simulation only while the second considered the retrieval strategy. The experimental results showed the effectiveness of the proposed system in enhancing academic achievement for organizational learners more than for rehearsal learners.
\end{abstract}

\section{Keywords}

Simulations, teaching/learning strategies, improving classroom teaching.

\section{INTRODUCTION}

Studies have shown that changing a traditional teaching approach such as lecturing to an interactive lecturing and teaching approach has proved to be feasible and to have a positive impact on the student's motivation [1]. The lecturing mode of teaching is based on one lecturer to many students, where there is normally minimal interaction. Web-based teaching achieves an interactive mode of teaching where students are engaged in the course of learning, through the various interactive materials designed and developed by these web-based teaching packages. Interactive teaching and learning via the Internet partially supplements the traditional lecture teaching method, by providing an interactive environment which is similar to the traditional lecture one, but which pays more attention to the students' individual needs [2]. It offers a better opportunity to provide more individualized instructions, with immediate and direct feedback on performance than can be offered by conventional teaching [3].

These advantages of web-based teaching and the increasing demand for a greater outreach of lecturers, for students, have resulted in the development of web-based multimedia packages. This coincided with the rapid acceptance of the Internet as a tool for disseminating information [4] and as a growing option with respect to serving as a study tool for students [5].

Many disciplines are re-evaluating their strategies and techniques in view of the services offered by the Internet [6]. Simulation is as much affected by this technology as other techniques, because it represents a fertile area for performing computer simulation research [7-8]. Kuljis and Paul go so far as to state that the pressure imposed by the proliferation of Web uses has forced the simulation community to migrate to the Web in order to stay "alive" [9]. Whether the Web has enabled, caused or forced the simulation community to move to the Web is open for debate, but one thing is clear: it has resulted in the emergence of the area of Web-based simulation (WBS) [10].

Web-based simulation is based on integration of the Web with the field of simulation and it has been growing rapidly during the past few years [11]. It is currently not an existing field, but rather an idea that represents the simulation practitioners' interest in exploiting Web technology. It can be defined as using the resources and technologies offered by the World Wide Web (WWW) in achieving interaction with clients, server modeling, and simulation tools. [12].

Many researchers emphasize the importance of web-based simulation [10, 13-14]. To make learning more efficient, many powerful personalized/adaptive guidance mechanisms have been proposed [15-18). Some researchers also emphasize that personalization should consider the levels of the learner's knowledge, especially in relation to the learning process. Given the fact that the abilities of individuals may be based on major fields and subjects, considering the learner's ability can promote personalized learning performance [18].

Few researches consider the learners' cognitive strategy in developing e-learning systems, so this requires activation of the researches dealing with integration between simulation and the different cognitive strategies, such as retrieval strategies, and studying their impact on the student's performance.

Retrieval strategies can be defined as behaviors and thoughts in which a learner engages and which are intended to affect the learner's encoding process [19].

Rehearsal strategies are employed by learners to remember the material using repetition; while organization is the process by which the learner organizes and builds connections among the items of information received in the learning environment [20]. The specific tactics associated with organization include the process of selecting the main idea through outlining, networking, and diagramming information [19]. In addition, many researchers have demonstrated the importance of retrieval strategies in the ability of learners to retrieve the educational material more efficiently [21-24].

The current research is considered one of the researches that integrate WWW-based simulation with retrieval strat egies to implement an e-learning system for the development of computer networking concepts. The proposed educational 
site explains computer networking concepts in two different formats, the first uses simulation only while the second considers the retrieval strategy. The main research aims which have motivated the conduction of this study are:

- Exploring the ways of designing WWW-based simulation which effectively support learning.

- Considering the learner retrieval strategy and integrating it into the WWW-based simulation.

- Examining the effectiveness of this integration on students' achievement

This paper consists of the following sections: Section 2 describes the proposed system; section 3 describes the experimental results; and section 4 describes the conclusion and future work.

\section{PROPOSED SYSTEM}

The design and development of the proposed system in this study was developed according to the ADDIE model (analysis, design, development, implementation, and evaluation) proposed by Dick, Carey, and Carey [25]. This proposed instructional model is based on the systematic development of instruction and learning to adapt with the independent variable, which is the subject matter of the current research (the integration between web-based simulation and retrieval strategies).

The proposed system has two main formats: the first depends on the web-based simulation only while the second considers the integration between web-based simulation and the retrieval strategy. Phases of the design and development process of the proposed system are illustrated as follows:

1. Analysis: The purpose of the first phase is to analyze the requirements and information needed for establishing goals and necessary contents. Concurrently, the domain and user characteristics are analyzed to establish a profile of the learner and the system environment. The learner's characteristics specify the learner's abilities, preferences, and existing knowledge, that determine the content choice according to the learner's existing knowledge while the learner's preferences and system context are taken into account in multimedia choice. The output of these stages feeds into multimedia selection and integration, which match the specification of the content to available multimedia resources. The characteristics of the learners were determined, including their previous academic levels and cognitive strategies used in the information retrieval. The output of this phase: Eight general objectives include 61 cognitive objects and practical skills. Learning contents include the following: Computer network, classification of Computer network, Communication tools in network, local area network, network cards, network protocols, network layers, and network topologies. The concept map of the introduced concepts in the proposed system is shown in Figure 1 and the information types are illustrated in figure 2 .

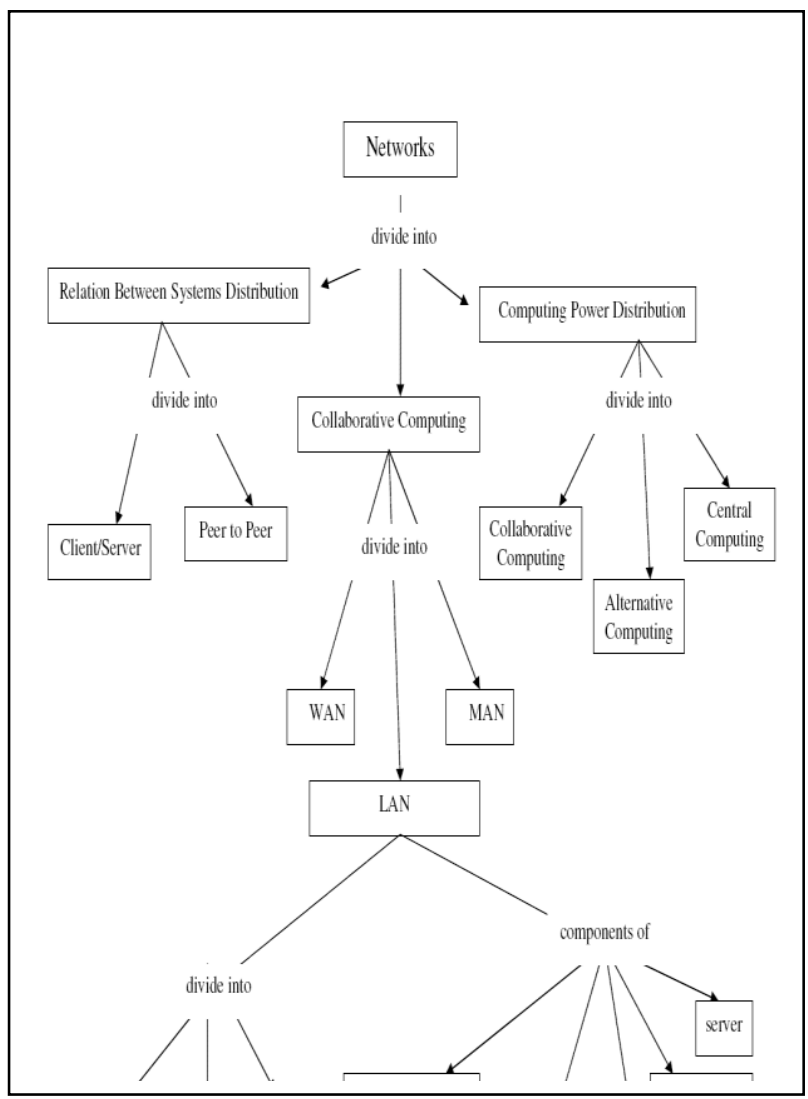

Fig. 1: concept map of the contents

Task analysis is considered to establish the details of the main tasks and to help in making the educational scenario. The main tasks were divided into 60 sub-tasks. The analysis of requirements determines the specifications of the needed computer systems and peripherals.

2. Design: The outcome of analysis is used to create a blueprint for the instruction, and define the learning strategy (mastery learning). The main scenario of the proposed educational website is introduced through screen by screen storyboard according to educational and technical specifications. 


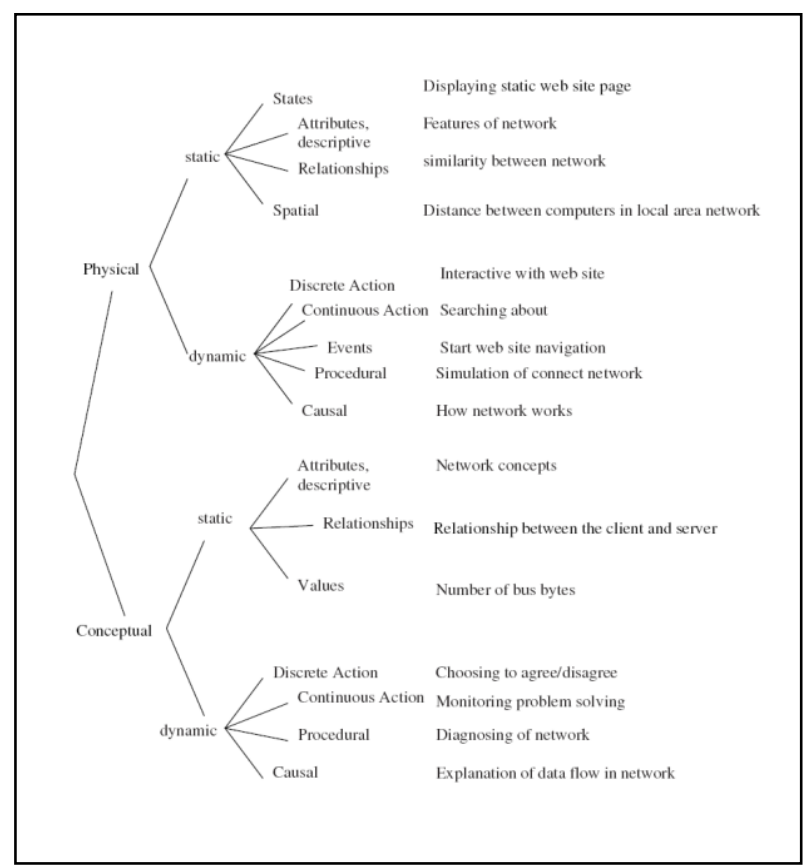

Fig. 2: information types

Designing the proposed system includes tools such as (mail forms, search tools, a dictionary, timer, e-book, chat tool to support synchronized interactivity, and a forum to support unsynchronized interactivity). It also includes scales such as (retrieval strategies scale, and the electronic achievement tests), which consist of theoretical and practical activities, styles of interaction which are shown in figure 3, graphical user interface considering the navigation through the web pages, and contents distribution on the learning pages.

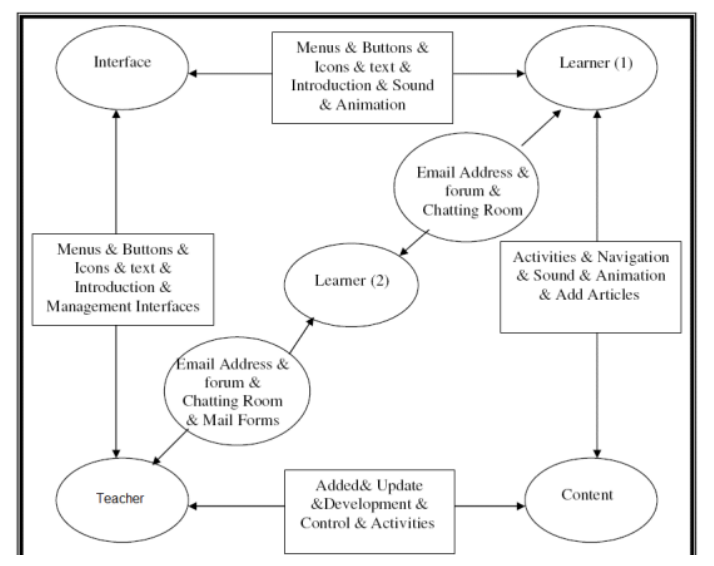

Fig. 3: Styles of Interaction Through the proposed System

Architecture of the proposed system is illustrated in figure 4.The system consists of lessons based on simulation, utility pages, and database includes forum $\mathrm{DB}$, chatting $\mathrm{DB}$, and questions DB. Two different formats are designed, the first uses simulation only while the second considers the retrieval strategy through theoretical and practical activities. Learners interact with themselves and with their teacher through a set of collaboration ways such as chat, e-mails. Utility tools

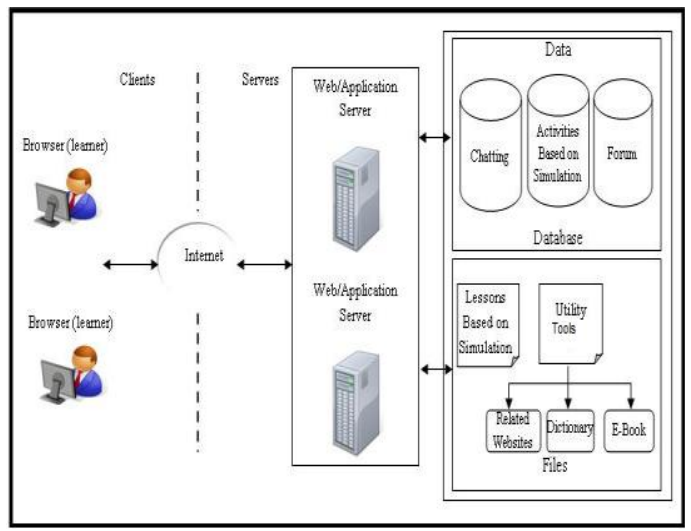

Fig. 4: Architecture of E-Learning System

3. Development: This phase describes the tools used to teach, the materials, strategies, event sequences, and necessary resources mentioned in the previous step. These are all put into action.

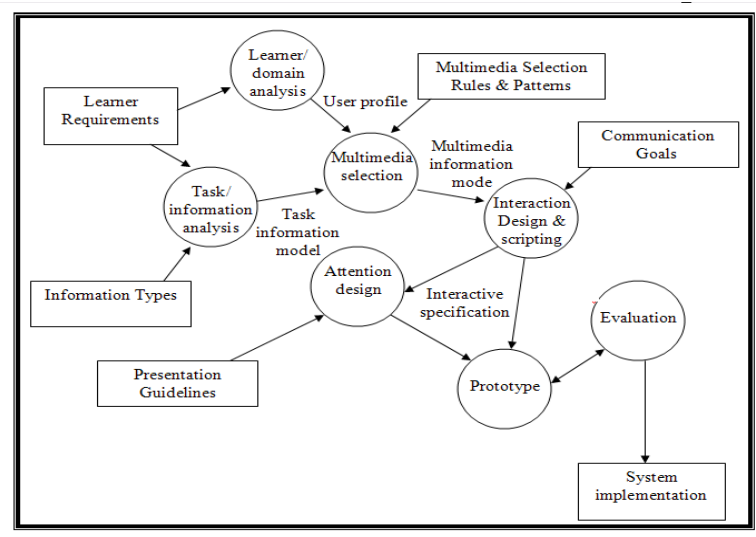

Fig. 5: system flow diagram

4. Implementation: This phase involves building the software of the proposed e-learning system. Several software programs were used for certain purposes. Macromedia dream weaver CS was used for designing web pages and special pages of the tutorial; Macromedia flash CS for animation design; Adobe Photoshop CS for editing images; Edraw network diagram 5 for designing the networks diagrams; Flash chat for creating chat rooms, and Microsoft FrontPage for producing web pages such as homepages, activity pages, and sitemaps. Microsoft Office Word was used for producing both the electronic book, and dictionary pages; while Microsoft Office Access for managing the system database, and Action Script for designing the educational activities. Both ASP and HTML were used to design web pages such as mail forms, and reports from learners. Sothink DHTML Menu was used to create a tool list on the website; E-Book Workshop was used to publish the e-book on the website; and HTML Password Lock was used to provide security. Finally, Articulate Quizmaker was used to generate electronic test.

Figure 6 shows the interaction through the proposed system. 


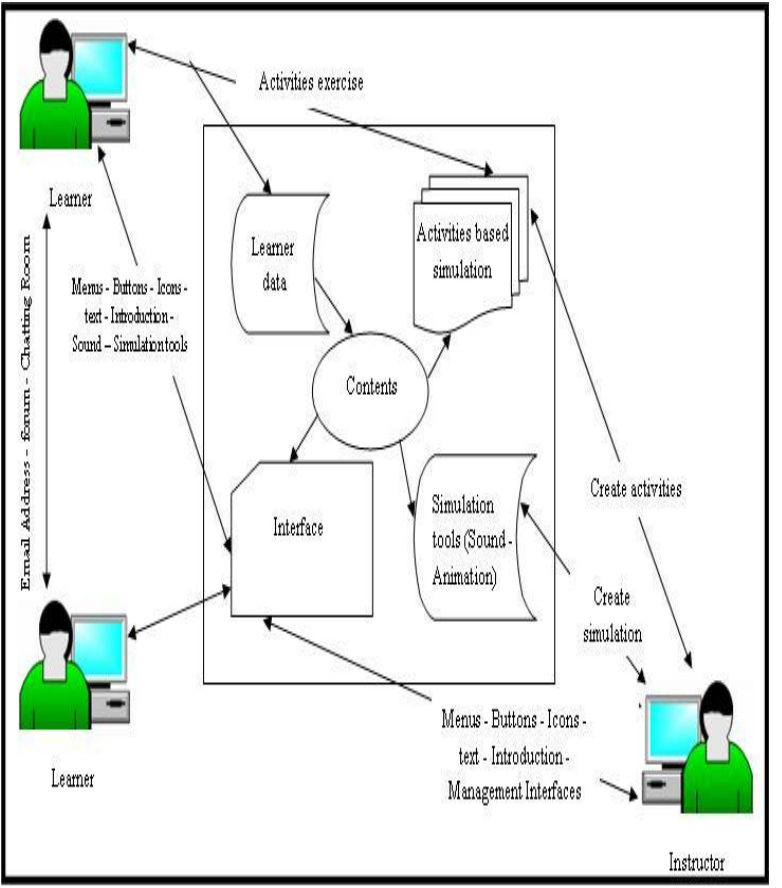

Fig. 6: Interaction through the System

5. Evaluation: This phase aimed to insure the validity of the proposed system. The system consists of two websites, the first was one based on simulation only while the second considered the learner retrieval strategy. The components' test was applied to check the individual component, followed by the integration test and finally the functional test. Evaluation scale was designed; both peers and specialists were exposed to them, and the results of their comments and suggestions were considered. Suggestions about clarity of photos, animation (2D and 3D), and presentation of materials were all taken into account in the final version of web-based simulation system before the experimental groups learners were exposed to it.

\section{Experimental Results}

To verify the effectiveness of the proposed system, an experiment was employed. The experimental group learners are selected randomly. All the learners were first exposed to pre-test to check their knowledge baseline in computer networking concepts and make sure of the group equivalence. A retrieval scale contains 30 items was applied to specify the rehearsal and organizational learners. Then the experimental group (60 learners) was exposed to the proposed system. Learners were divided into 4 sub-groups. The first comprised the organizational learners exposed to the webbased simulation; the second comprised the organizational learners exposed to the web-based simulation integrated with the retrieval strategy; the third comprised the rehearsal learners exposed to the web-based simulation; and the fourth comprised the rehearsal learners exposed to the web-based simulation integrated with the retrieval strategy. The experimental design is illustrated in table 1 .
Table 1.Experimental design

\begin{tabular}{|c|c|c|}
\hline Simulation & simulation & $\begin{array}{c}\text { simulation with } \\
\text { retrieval } \\
\text { strategy }\end{array}$ \\
$\begin{array}{c}\text { Retrieval } \\
\text { strategies }\end{array}$ & Group-1 & Group-2 \\
\hline Organizational & & Group-4 \\
\hline strategy & Group-3 & . \\
\hline
\end{tabular}

The experimental group's learners learn through the proposed system at the laboratory under the supervision of a teacher. It was found that the learners spent a regular period in reading the contents of attractive web pages; while they skipped web pages, because they were distracted by something else like chatting with other learners. The learning effectiveness calculation algorithm was used to determine the learning effectiveness, according to the approved method of e-learning effectiveness calculation [26-27]. Figure 7 represents the flow diagram of each learner's online learning effectiveness calculation. The input $\mathrm{Ti}$, shown on the upper-left of the figure represents the time spent by learner $\mathrm{X}$ in browsing the web page during his/her online learning activities. The system measured the effective learning time for learners and displayed the time when they were requested by the teacher to determine the problems or difficulties they had during the implementation.

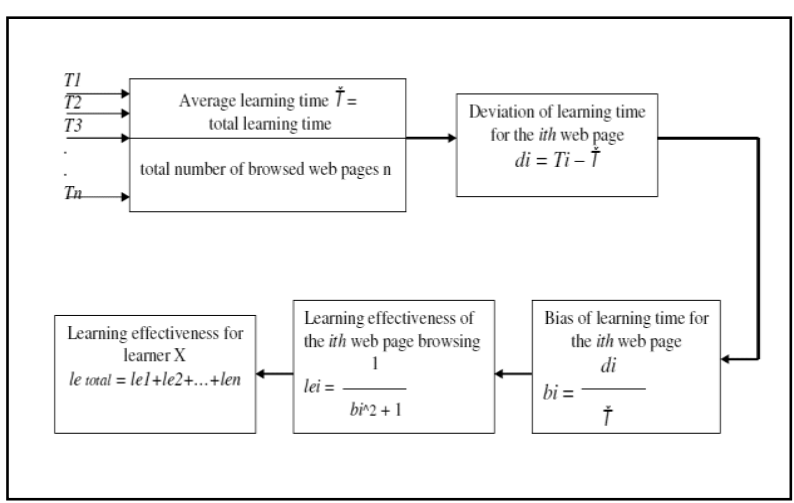

Fig. 7: Flow Diagram of Each Learner's Online Learning Effectiveness Calculation 
The experiment was conducted at the over 30 days after which the achievement test was applied. To develop the achievement test, a table of item specifications (which reflects the content and learning outcomes) was constructed. The achievement test contained 60 items, which were written to accurately reflect the cognitive levels encouraged in the content. Reliability coefficient was 0.94 and the level of difficulty for the test items ranged from 0.22 to 0.61 .

Table 2 summarizes the results of the experimental group's achievement in the post test.

Table 2. Post-test results for experimental groups.

\begin{tabular}{|c|c|c|}
\hline Experimental group & Mean & Std.Dev. \\
\hline Group-1 & 11.21 & 5.00 \\
\hline Group-2 & 22.47 & 3.18 \\
\hline Group-3 & 13.00 & 5.07 \\
\hline Group-4 & 17.83 & 4.86 \\
\hline
\end{tabular}

SPSS program was used for the statistical analysis of the obtained results. Two-Dimensional Analysis of Variance (ANOVA) was applied and it arrived at the following conclusions:-

- There is a significant difference between group 1 and group 2 at significant level 0.05 , which indicates the efficiency of the integration between WWW simulation and retrieval strategy for the organizational learners.

- There is not a significant difference between group 1 and 3 at significant level 0.05 (exposed to simulation only), which indicates the equivalent improvement of both the rehearsal learners and organizational learners. This can be interpreted in the light of the existence of many utility tools in the proposed system such as dictionary, e-book, related websites where learners study the content through different ways.

- There is a significant difference between the four groups at significant level 0.05 , in favor of group 2 . This indicates the efficiency of the integration between WWW simulation and retrieval strategy for the organizational learners rather than rehearsal learners.

\section{CONCLUSIONS AND FUTURE WORK}

This paper investigates the impact of the integration between retrieval strategy and WWW simulation, as the statistical analysis of the learners' results indicates their significant improvement with respect to their achievement. In addition, results show the effectiveness of the proposed system in enhancing academic achievement for organizational learners more than for rehearsal learners.

For future work, an online testing system will be included to give the pupils a quiz, directly after the end of learning activities on the e-learning platform to reflect the effectiveness of the purification process of the parameters extracted from the learners' learning profiles.

\section{REFERENCES}

[1] Van Dijk, L. A., \& Jochems, W. M. G. 2002. "Changing a traditional lecturing approach into an interactive approach: Effects of interrupting the monologue in lectures". International Journal of Engineering Education, 18(3), 275-284.

[2] Oreta, A. W. C. 1999. " Developing a web-based learning module in a basic civil engineering course". Computer Applications in Engineering Education, 7(4), 235-243.

[3] Ng, C., Choy, S., Kwan, R., \& Chan, S. 2005. "A WebBased Environment to Improve Teaching and Learning of Computer Programming in Distance Education", ICWL 2005, LNCS 3583, pp. 279 - 290. Available from www.springerlink.com/index/e40r86uk7unrwxau.pdf.

[4] Lee, M. G. 2001. "Profiling students_adaptation styles in web-based learning". Computers \& Education, 36, 121132.

[5] Grabe, M., \& Sigler, E. 2002. "Studying online: Evaluation of an online study environment". Computers \& Education, 38, 375-383.

[6] Alfonseca, M. J., \& Vangheluwe, H. 2001. Web-based simulation of systems described by partial differential equations. In Proceedings of the 33rd Conference on Winter Simulation, Arlington, Virginia, USA, pp. 629 636.

[7] Fishwick, P.A. 1997. Web-based simulation, in: S. Andradttir, K.J. Healy, D.H. Withers, B.L. Nelson (Eds.). Proceedings of the 29th Conference on Winter Simulation, Atlanta, Georgia, USA, pp. 100-102.

[8] Miller, A., Fishwick, P.A. , Taylor, S.J.E., Benjamin P., \& Szymanski, B. 2001. "Research and commercial opportunities in web-based simulation". Simulation Practice and Theory (9), (1-2), 55-72.

[9] Kuljis, J., \& Paul, R.J. 2001. "An appraisal of web-based simulation: whither we wander?". Journal of Simulation Practice and Theory, 9 (1-2), pp.37-54

[10] Byrne, J., Heavey, C.,\& Byrne, P. 2010. "A review of Web-based simulation and supporting tools". Simulation Modeling Practice and Theory, 18, 253-276.

[11] Huang, Y., Madey, G. 2005. Autonomic web-based simulation. In Proceedings of the 38th Annual Symposium on Simulation (ANSS'05), IEEE Computer Society, Washington, DC, USA, pp. 160-167.

[12] Bencomo, S.D. 2004. "Control learning: present and future". Annual Reviews in Control 28 (1), 115-136.

[13] Nickrson, j. v. 2006. "A model for evaluating the effectiveness of remote engineering laboratories and simulation in education". Computers \& Education, Volume 49, Issue 3, 545-942.

[14] Yu-Hui, T. , Shin-Ming, G., Ya-Hui, L. 2006. "The design and the formative evaluation of a web-based course for simulation analysis experiences". Computers \& Education (47), 414-432.

[15] Chen, C.-M., Lee, H.-M., \& Chen, Y.-H. 2005. "Personalized e-learning system using item response theory". Computers and Education, 44(3), 237-255. 
[16] Shiou-Wen Y., \& Jia-Jiunn L. 2005. "Assessing met cognitive knowledge in web-based CALL: a neural network approach", Computers \& Education (44), 97113.

[17] Chen, C.M., Liu, C.-Y., \& Chang, M.-H. 2006. "Personalized curriculum sequencing using modified item response theory for web-based instruction". Expert Systems with Applications, 30(2), 378-396.

[18] Chen, C. M. 2008. "Intelligent web-based learning system with personalized learning path guidance". Computers \& Education, 51, 787-814

[19] Weinstein, C.E., \& Mayer, R.E. 1986. The teaching of learning strategies. In M. Wittrock (Ed.), Handbook of research on teaching. New York, NY: Macmillan.

[20] Olgren, C.H. 1998. Improving learning outcomes: The effects of learning strategies and motivation. In C. Campbell Gibson (Ed.), Distance learners in higher education: Institutional response for qualitv outcomes .Madison, WI: Atwood Publishing.

[21] Mcbride, S.D., \& Dwyer, F.M. 1982. The Effect of Organizational Chunking and Retrieval Strategies in Facilitating Learning and Recall of Cognitive Learning Tasks, ERIC. Available from :http://www.eric.ed.gov/ERICWebPortal/custom/portlets /recordDetails/detailmini.jsp?_nfpb=true\&_\&ERICExtSe arch_SearchValue_0=ED223202\&ERICExtSearch_Sear chType_0=no\&accno=ED 223202
[22] Glenn, L., \& Jerry, D. 1983. "Effects of Encoding and Retrieval Strategies on The Recall of Learning Disabled and Normal Children". Journal of general psychology, volume 109, pp.233.

[23] O'Neill, M. E. \& Douglas, V.I. 1996. "Rehearsal Strategies and Recall Performance in Boys with and Without Attention Deficit Hyperactivity Disorder". Journal of Pediatric Psychology. Vol. 21, No. 1, pp. 7388

[24] Ikier, S., Yang, L., \& Hasher, L. 2008. "Implicit Proactive Interference, Age, and Automatic Versus Controlled Retrieval Strategies". Psychol. Sci. May, 19(5), 456-61.

[25] Dick, W., Carey, L., \& Carey, J. O., 2001. The Systematic Design of Instruction, 5th ed., New York: Addison-Wesley, Longman.

[26] Huang, J., Chu, S., \& Guan, T. 2007. "Implementation and performance evaluation of parameter improvement mechanisms for intelligent e-learning systems". Computers \& Education, 49(3), 597-614.

[27] Michail N. G. 2010. The Evaluation of an e-learning Web-Based Platform. In Proceedings of the 2nd International Conference on Computer Supported Education, pp. 433-438. 